\title{
New Advances in Gold Catalysis Part II*
}

\author{
David Thompson \\ $\overline{\text { Consultant to World Gold Council and Technical Editor, Gold Bulletin }}$ \\ 'Newlands', The Village, Whitchurch Hill, Reading, RG8 7PN, UK
}

\begin{abstract}
Some of the unique features of gold catalysis were described in Part 1. Further examples of reactions catalysed by supported transition metal oxides are given in this second part. These include both selective and complete oxidation of hydrocarbons and a number of hydrogenation reactions. In fact, gold has now been demonstrated to be the element of choice for some catalytic reactions. As a result, both chemical processing and environmental applications are foreseen for supported gold catalyst systems. In this, the second of two articles, the overall current state of knowledge on gold catalysis is reviewed and some early examples of homogeneous gold catalysis, in solution, assessed.
\end{abstract}

\section{HETEROGENEOUS CATALYSIS}

We have seen from the work described in Part I (1) that gold species supported on activated carbon are the most active for the hydrochlorination of acetylene (ethyne), and that $\mathrm{Au} / \alpha-\mathrm{Fe}_{2} \mathrm{O}_{3}$ is the best catalyst found to date for the oxidation of carbon monoxide at low temperatures. The control of gold particle size to ca 2-5 $\mathrm{nm}$ is important and this can be achieved using deposition precipitation or co-precipitation preparative procedures for the catalysts.

In Part II of this pair of articles we will consider other heterogeneous reactions catalysed by gold, including catalytic combustion of hydrocarbons, selective oxidation, hydrogenation of carbon oxides, the reduction of nitrogen oxides with propene, carbon monoxide or hydrogen, and the oxidative decomposition of halogen compounds.

\section{Catalytic Combustion of Hydrocarbons}

Waters et al (2) have evaluated co-precipitated gold on transition metal oxide catalysts for their activity towards methane oxidation to carbon dioxide and water. Activities were found to fall in the following order:

$$
\mathrm{Au} / \mathrm{Co}_{3} \mathrm{O}_{4}>\mathrm{Au} / \mathrm{NiO}>\mathrm{Au} / \mathrm{MnO}_{\mathrm{x}}>\mathrm{Au} / \mathrm{Fe}_{2} \mathrm{O}_{3}
$$

$5 \% \mathrm{Au} / \mathrm{Co}_{3} \mathrm{O}_{4}$ is active at below $523 \mathrm{~K}$. A dual site mechanism was proposed to explain the results since the catalyst systems are also active at higher temperatures. The activities increased with increased oxidation state of gold.
Haruta (3) has shown (Figure 1) that catalytic activity, as expressed by temperature at 50\% conversion, for the oxidation of methane $\left(\mathrm{CH}_{4}\right)$

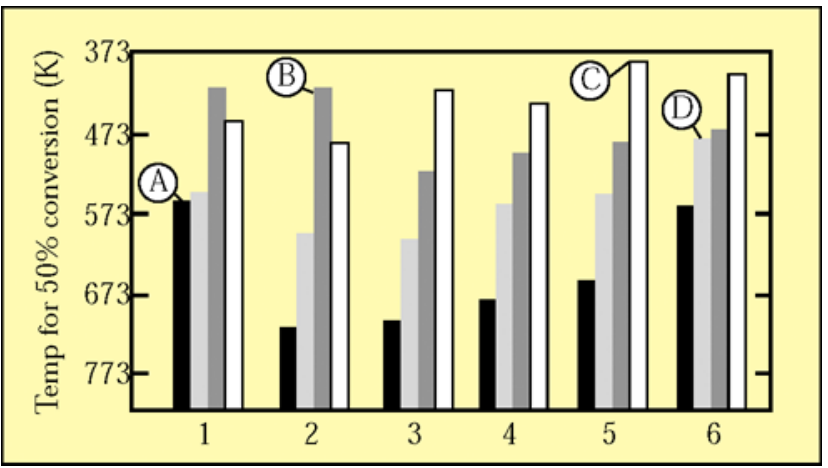

Figure 1 Temperature for $50 \%$ conversion in the catalytic combustion of hydrocarbons and trimethylamine. ${ }_{1} \mathrm{w} \% \mathrm{Pd} / \mathrm{Al}_{2} \mathrm{O}_{3}$ and $\mathrm{Pt} / \mathrm{Al}_{2} \mathrm{O}_{3}$ were prepared by impregnation. 1:19 Aulsupport catalysts were prepared by co-precipitation and calcined in air at $673 \mathrm{~K} .1$ Iwt $\% \mathrm{Pd} / \mathrm{Al}_{2} \mathrm{O}_{3}: 2$ 1wt\% $\% \mathrm{Pt}_{2} \mathrm{O}_{3}$ : $310 \mathrm{w} \% \mathrm{Au}^{2} \mathrm{Fe}_{2} \mathrm{O}_{3} ; 410 \mathrm{wt} \% \mathrm{Au} / \mathrm{ZnFe} \mathrm{O}_{2}$;

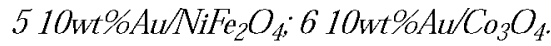
A: methane; $B$ : propene; $C$ : trimethylamine; $D$ : propane. The concentrations of reactant gases in air were: $\mathrm{CH}_{4}: 0.25 \mathrm{vol} \% ; \mathrm{C}_{3} \mathrm{H}_{8}$ and $\mathrm{C}_{3} \mathrm{H}_{6}: 0.1 \mathrm{vol} \%$; $\left(\mathrm{CH}_{3}\right)_{3} \mathrm{~N}: 0.05 \mathrm{vol} \%$; balanced with air to $1 \mathrm{~atm} ; \mathrm{SV}$ $2 \times 10^{4} \mathrm{ml}(\mathrm{g} \text { cat })^{-1} \mathrm{~h}^{-1}$. (Based on reference 3)

* The material for this article is based on the second part of a talk presented at the IPMI Annual Meeting in Toronto, 17 June 1998 which has now been published as part of the Precious Metals 1998 'Proceedings of the Conference held in Toronto, Ontario, Canada'. 
propane $\left(\mathrm{C}_{3} \mathrm{H}_{8}\right)$, and propene $\left(\mathrm{C}_{3} \mathrm{H}_{6}\right)$ decreases in the order:

$$
\mathrm{Au} / \mathrm{Co}_{3} \mathrm{O}_{4}>\mathrm{Au} / \mathrm{NiFe}_{2} \mathrm{O}_{4}>\mathrm{Au} / \mathrm{ZnFe}_{2} \mathrm{O}_{4}>\mathrm{Au} / \mathrm{Fe}_{2} \mathrm{O}_{3}
$$

In the oxidation of methane and propane the supported gold catalysts are more active than the $\mathrm{Pt} / \mathrm{Al}_{2} \mathrm{O}_{3}$ catalyst. The most highly active gold catalyst, ie $\mathrm{Au} / \mathrm{CO}_{3} \mathrm{O}_{4}$ gives approximately the same level of activity as a commercial $\mathrm{Pd} / \mathrm{Al}_{2} \mathrm{O}_{3}$ catalyst. Gold should therefore be considered along with palladium and platinum for the complete oxidation of saturated hydrocarbons. For the complete oxidation of unsaturated hydrocarbons, such as propene, platinum and palladium are more active than supported gold catalysts. Figure 1 also includes conversions for trimethylamine, an indicator for the removal of odours from gas streams.

\section{Selective Oxidation}

Haruta (4) found that for the oxidation of propene to propene oxide, greater than $99 \%$ selectivities could be obtained at low conversions (1\%) using $1 \mathrm{wt} \% \mathrm{Au} / \mathrm{TiO}_{2}$ at $323 \mathrm{~K}$. The feed gas was hydrogen / oxygen / propene / argon in the ratio $10: 10: 10: 70 \mathrm{vol} \%$ at a flow rate of $2 \times 10^{3} \mathrm{ml} \mathrm{h}^{-1}$, using $0.5 \mathrm{~g}$ catalyst. The catalyst was prepared by deposition precipitation. Similar palladium and platinum catalysts produced no propene oxide under similar conditions. As with gold catalyst systems used in complete oxidation reactions, the method of preparation was again found to be important and best results were obtained when the gold particles had a mean particle diameter of $2.4 \mathrm{~nm}$ and a narrow size distribution. More research is now required regarding means for achieving high selectivity at higher conversions, although a recycle process using a low conversion situation could also be considered.

\section{Hydrogenation of Carbon Oxides}

If gold supported on zinc oxide is prepared by coprecipitation, it gives methanol from the hydrogenation of carbon monoxide and carbon dioxide (4), while other noble metal catalysts give methane as the principal product. The selectivity and activity differ only a little amongst the Group 11 metals; basic metal oxides such as $\mathrm{ZnO}$ are the best for production of methanol, whilst acidic metal oxide supports, eg $\mathrm{TiO}_{2}$, give carbon monoxide via reverse water gas shift at much higher rates. In Figure 2 the methanol yield is given as a function of the reaction temperature in the hydrogenation of carbon dioxide, for a number of supported gold catalysts. The

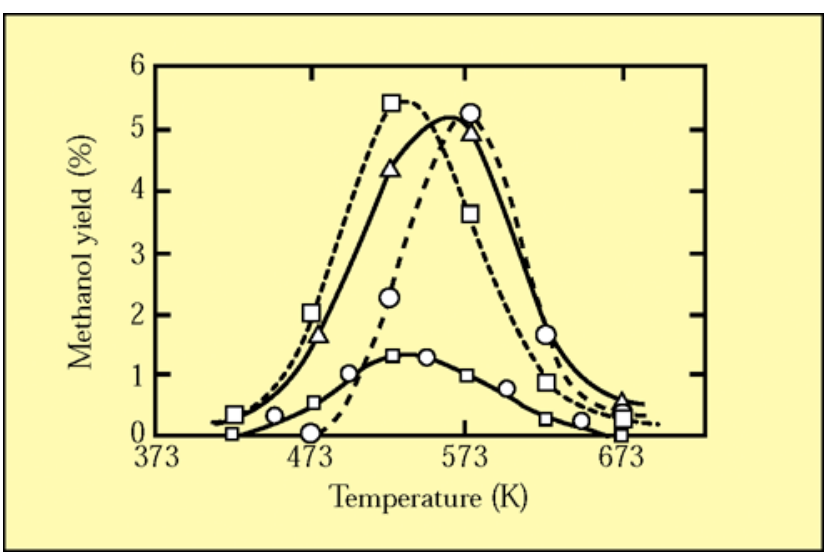

Figure 2 Methanol yield as a function of reaction temperature in the hydrogenation of carbon dioxide over supported gold catalysts. $\mathrm{Au} / \alpha-\mathrm{Fe}_{2} \mathrm{O}_{3}(\square) ; \mathrm{Cu} / \mathrm{ZnO}(\triangle)$; $A u / Z n O(O): A u / T_{i} O_{2}(\bigcirc \square): A u / M(M=F e, Z n$, Ti) $=1: 19 . \mathrm{CO}_{2}: H_{2}: A r=23: 67: 10 ; 50 \mathrm{~atm}$ pressure; $S V=3000 \mathrm{ml}(\mathrm{g} \mathrm{cat})^{-1} \mathrm{~h}^{-1}$. (Based on reference 4)

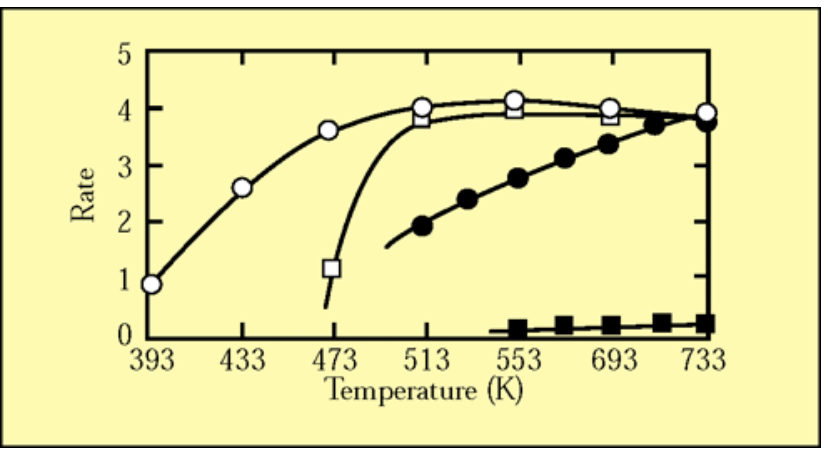

Figure 3 Temperature dependence of the catalytic activity of supported gold and base metal oxide catalysts in the Water Gas Shift. Starting reaction gas mixture was 4.88 vol\% carbon monoxide in argon; water vapour partial pressure 223 Torr; SV $4000 \mathrm{~h}^{-1}$; latm. Aw $\alpha$ $\mathrm{Fe}_{2} \mathrm{O}_{3}(\mathrm{O}) ; \mathrm{CuO} / \mathrm{ZnO} / \mathrm{Al}_{2} \mathrm{O}_{3}(\square) ; \alpha-\mathrm{Fe}_{2} \mathrm{O}_{3}(\mathrm{O})$; $\mathrm{Au}_{\mathrm{Al}} \mathrm{O}_{3}$ (ם). Rates are expressed in $\mathrm{mol} \mathrm{m}^{-2} \mathrm{~h}^{-1}{ }_{X}$ $10^{-2}$. (Based on reference 6$)$

activity per unit surface area increases with decreasing particle diameter of the gold (5).

The use of $\mathrm{Au} / \alpha-\mathrm{Fe}_{2} \mathrm{O}_{3}$ in the catalysis of the water gas shift has been reported by Andreeva et al (6, 7) (Figure 3). The gold particles had an average size of $3.5 \mathrm{~nm}$ and were situated in close proximity to the iron oxide crystallites. The gold on iron oxide catalyst was active at low temperatures, and its performance overall compares favourably with the $\mathrm{CuO} / \mathrm{ZnO} / \mathrm{Al}_{2} \mathrm{O}_{3}$ catalyst which is commercially well established for this reaction. Haruta et al (8) have also reported catalysts active at low temperatures: gold supported on titania, 
prepared by deposition precipitation of gold hydroxide from chloroauric acid and titanium dioxide powder, was shown to be active for both the forward and the backward water gas shift.

\section{Reduction of Nitric Oxide with Carbon Monoxide, Hydrogen or Propene}

The reduction of nitric oxide with carbon monoxide in the absence of oxygen occurs at temperatures below $373 \mathrm{~K}$ over gold supported on $\alpha-\mathrm{Fe}_{2} \mathrm{O}_{3}$ or $\mathrm{NiFe}_{2} \mathrm{O}_{4}$, yielding nitrogen as the main product, while the product over unsupported gold is $\mathrm{N}_{2} \mathrm{O}$ (4). $\mathrm{Au}(\mathrm{I}) / \mathrm{ZSM}-5$ is also active for this reaction at low temperatures (9). Platinum Group Metals require higher temperatures and produce more nitrous oxide (4). The reaction between nitric oxide and carbon monoxide is deactivated by the presence of oxygen, but not by water (over $\mathrm{Au} / \alpha-\mathrm{Fe}_{2} \mathrm{O}_{3}$ ).

Salama et al (10 - 13) have studied the reduction of nitric oxide by carbon monoxide and hydrogen:

$$
2 \mathrm{NO}+\mathrm{CO}+\mathrm{H}_{2} \rightarrow \mathrm{N}_{2}+\mathrm{CO}_{2}+\mathrm{H}_{2} \mathrm{O}
$$

Freshly reduced $\mathrm{Au} / \mathrm{NaY}$ zeolite catalyst was used at 673 $\mathrm{K}$ and some of the results are illustrated in Figure 4.

The reduction of nitric oxide to nitrogen with propene takes place over several supported gold catalysts and is accelerated by the presence of oxygen and water (14): Figure 5 indicates that gold on zinc oxide, magnesia, titania, or alumina is active between 473 and $773 \mathrm{~K} . \mathrm{A}_{11} / \mathrm{Al}_{2} \mathrm{O}_{3}$ gives the highest conversion of nitric oxide to nitrogen. Over the $\mathrm{Au} / \mathrm{Al}_{2} \mathrm{O}_{3}$ catalyst nitric oxide is oxidized to nitrogen dioxide which then reacts with propene to give nitrogen. The addition of

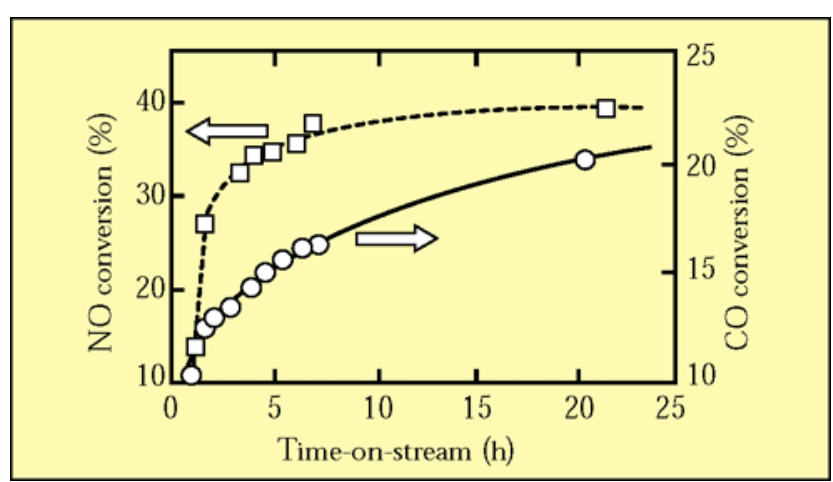

Figure 4 Conversion of nitric oxide and carbon monoxide to nitrogen and carbon dioxide respectively as functions of time on stream in the $\mathrm{NO} / \mathrm{CO} / \mathrm{H}_{2}$ reaction over Au/NaY zeolite at $673 \mathrm{~K}$. The inlet composition was $[\mathrm{NO}]=4810 \mathrm{ppm},[\mathrm{CO}]=\left[\mathrm{H}_{2}\right]=1 \%$. (Based on reference 10 )

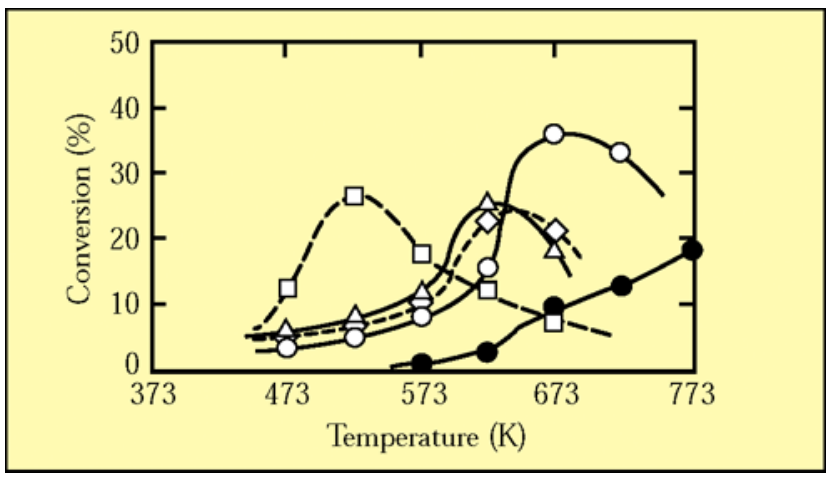

Figure 5 Temperature dependence of nitric oxide conversion to nitrogen using propene for $\mathrm{Au} / \mathrm{ZnO}(\square): \mathrm{Au} / \mathrm{TiO}_{2}$ $(\triangle): \mathrm{Au} / \mathrm{MgO}(\diamond) ; \mathrm{Au}_{\mathrm{Al}} \mathrm{O}_{3}(\mathrm{O}) ;$ and $\mathrm{Al}_{2} \mathrm{O}_{3}$ (O). Gold loading is $1.0 \mathrm{wt} \%$; reaction gas is nitric oxide 1000 ppm, propene $500 \mathrm{ppm}, 5.0$ vol\% oxygen, $1.8 \mathrm{vol} \% \mathrm{H}_{2} \mathrm{O}$, He balance; space velocity $2 \times 10^{4} \mathrm{ml}$ (g cat $)^{-1} h^{-1}$. (Based on reference 4)

$\mathrm{Mn}_{2} \mathrm{O}_{3}$ to the Au/alumina in order to enhance nitrogen dioxide formation, markedly improves the conversion of nitric oxide to nitrogen over a wide range of temperatures (15). This composite gold catalyst offers one of the best performances in nitric oxide conversion amongst the catalysts so far developed (see also A. Ueda and M. Haruta, Gold Bull., 1999, 32, 3 -this issue).

\section{Reactions with Halogenated Compounds}

Gold supported on cobalt oxide or alumina are claimed to be as active as platinum catalysts for the oxidative decomposition of dichlorodifluoromethane and methyl chloride (16). For example, 5wt\% $\mathrm{Au} / \mathrm{Co}_{3} \mathrm{O}_{4}$ can be used to completely decompose methyl chloride at around $600 \mathrm{~K}$.

\section{Gas purification}

In addition to the removal of carbon monoxide from air and other gas mixtures, other gas cleaning roles can be envisaged for supported gold catalysts, eg hydrogen has been removed from carbon dioxide feed gas, used in the production of urea, using gold supported on iron oxide prepared using a co-precipitation technique (17).

\section{PREPARATION AND CHARACTERIZATION OF SUPPORTED GOLD CATALYSTS}

It has gradually emerged over the years that careful preparation of gold and gold alloy catalysts is a key to obtaining repeatability in their performance. In describing 
the activity of bimetallic catalysts in 1985, Schwank (18) concluded that "The nature of the support and the preparative conditions play a decisive role in determining the microstructural characteristics of the active catalyst surface. In many cases gold seems to act more or less as an inert diluent, and ensemble or cluster effects seem to dominate the catalytic behaviour. These ensemble effects can be used to manipulate catalytic activity".

The importance of careful preparation has been emphasized much more recently by two of the leaders of research in heterogeneous gold catalysis, Haruta (4) and Hutchings (19). Haruta has described the adsorption properties and reactivities of gold in terms of their size dependency from bulk to fine particles.

The catalytic performance of gold markedly depends on dispersion, supports and preparation methods. When gold is deposited on selected metal oxides as hemispherical ultrafine particles with diameters smaller than $5 \mathrm{~nm}$, it exhibits surprisingly high activities and/or selectivities in the combustion of carbon monoxide and saturated hydrocarbons, the oxidation/decomposition of amines and organic halogen compounds, the partial oxidation of hydrocarbons, the hydrogenation of carbon oxides, unsaturated carbonyl compounds, alkynes and alkadienes, and the reduction of nitrogen oxides. In both the selective oxidation of propene and the complete oxidation of carbon monoxide, gold particle sizes in the range $2-5 \mathrm{~nm}$ give the highest turnover frequencies and product yields (4).

Hutchings (19) emphasized the importance of Haruta's work, confirming that for low temperature carbon monoxide oxidation the method used for catalyst preparation was crucial. Co-precipitation and deposition precipitation have been shown to be the best preparative methods, producing hemispherical particles strongly attached to the oxide support. Haruta showed that gold catalysts prepared using a conventional impregnation procedure are considerably less active than platinum group metals catalysts prepared in a similar way, but if a co-precipitation procedure was utilized, high activity catalysts were obtained with gold. The catalysts were prepared from addition of an aqueous solution of chloroauric acid and a metal nitrate to an aqueous sodium carbonate solution. The precipitate was then washed, vacuum dried and calcined at $673 \mathrm{~K}$. In addition, Haruta (20) has also shown that catalysts can be prepared using deposition precipitation. A uniform dispersion of small gold particles on the support is a necessary characteristic for good performance. The best results are obtained when reaction temperatures are $>328 \mathrm{~K}$ (4). Direct comparison with other precious metals is not necessarily available because impregnation is the most commonly used technique for these metals.

The influence of preparation methods on the catalytic activity for carbon monoxide oxidation was found to be very large for $\mathrm{Au} / \mathrm{TiO}_{2}$ and negligible for $\mathrm{Pt} / \mathrm{TiO}_{2}$ catalysts (21). Platinum and gold were deposited on titania by deposition precipitation, photodecomposition and impregnation. The deposition precipitation method gave the most active catalysts for both platinum and gold. Gold catalysts prepared by deposition precipitation were active at temperatures below $273 \mathrm{~K}$ and showed a much greater activity than platinum catalysts.

It is clear that gold dispersed on transition metal oxide has an intimate interaction with the support. Gold alone is less active as a catalyst than supported gold. Until recently much of the literature on the topic has assumed that metallic gold is the active species, but the present reviewer would like to highlight the possibility of a monolayer of gold oxide being present on the surface of the gold during oxidation reactions (22). The interface between the gold and the support and the interaction between the gold and the support also appear to be important (21). The activities are affected by the pretreatment procedures and recent work indicates that higher activities are obtained if the supported gold is not calcined (23-25).

\section{HOMOGENEOUS CATALYSIS}

Involvement of gold complexes of any type in homogeneous catalysis is very rare, and there are only a limited number of known examples. The rarity of examples is in marked contrast to those for the platinum group metals, many of which readily undergo catalytic oxidative-addition / reductiveelimination cycles (26). This has been rationalized by saying that this type of catalysis requires a very delicate balance between the stabilities of the two oxidation states involved, and this has not often been achieved for gold. An additional factor is thought to be the reluctance of gold to form hydride complexes, so that the oxidation of gold(I) by dihydrogen, or the formation of alkene complexes by $\beta$-elimination in gold(III)-alkyl complexes are virtually unknown (there is one case recorded of a tert-butyl iso-butyl isomerization, thought to occur by $\beta$-elimination (27)). Although gold(I) complexes readily undergo oxidative addition, $e g$ with alkyl halides, the resulting 
complexes have appeared to be either too stable to react further or so unstable that they react immediately. Reductive-elimination from di- or tri-organogold(III) complexes is either restricted to particular types of organogold complex or requires robust treatment resulting primarily in elimination of hydrocarbons by coupling reactions. For other precious metals, the relative stabilities of the two critical oxidation states have been successfully adjusted by appropriate choice of ligands, eg the inclusion of a good $\pi$-bonding ligand,

\section{Carbonylation of Olefins:}

Olefins $+\mathrm{CO} \longrightarrow t-\mathrm{RCO}_{2} \mathrm{H}$

Catalyst:

$$
\begin{aligned}
& \mathrm{Au}_{2} \mathrm{O}_{3} \stackrel{\mathrm{H}_{2} \mathrm{SO}_{4}}{\longrightarrow} \mathrm{Au}^{3+}(\mathrm{solv}) \stackrel{\mathrm{CO}}{\longrightarrow} \mathrm{Au}^{+}(\mathrm{solv}) \\
& \stackrel{\mathrm{CO}}{\longrightarrow}[\mathrm{Au}(\mathrm{CO})]^{+} \underset{-\mathrm{CO}}{\stackrel{\mathrm{CO}}{\rightleftharpoons}}\left[\mathrm{Au}(\mathrm{CO})_{2}\right]^{+}
\end{aligned}
$$

Figure 6 Catalyst for the carbonylation of olefins in sulfuric acid. (Based on reference 29) such as carbonyl, increases the stability of the lower oxidation state. In the case of gold $\pi$-bonding has seemed to be of relatively little importance.

The status for homogeneous catalysis by gold has, however, been dramatically transformed by the recently reported results of Teles et al (28). This BASF group have described the use of cationic gold (I) complexes of the type $\left[\mathrm{L}-\mathrm{Au}^{+}\right]$(where $\mathrm{L}$ is a phosphine, phosphite or an arsine) for the addition of alcohols to alkynes. An example of such a reaction is given below:<smiles>CCC#CCC</smiles>

The turnover numbers for this type of reaction were found to be up to $10^{5}$ moles of product per mole of catalyst, with turnover frequencies of up to $5400 \mathrm{~h}^{-1}$. These gold catalyst systems are a significant improvement on the mercury catalysts used previously and the reactions are conducted under mild conditions $(293-323 \mathrm{~K})$ in the presence of acid co-catalysts.

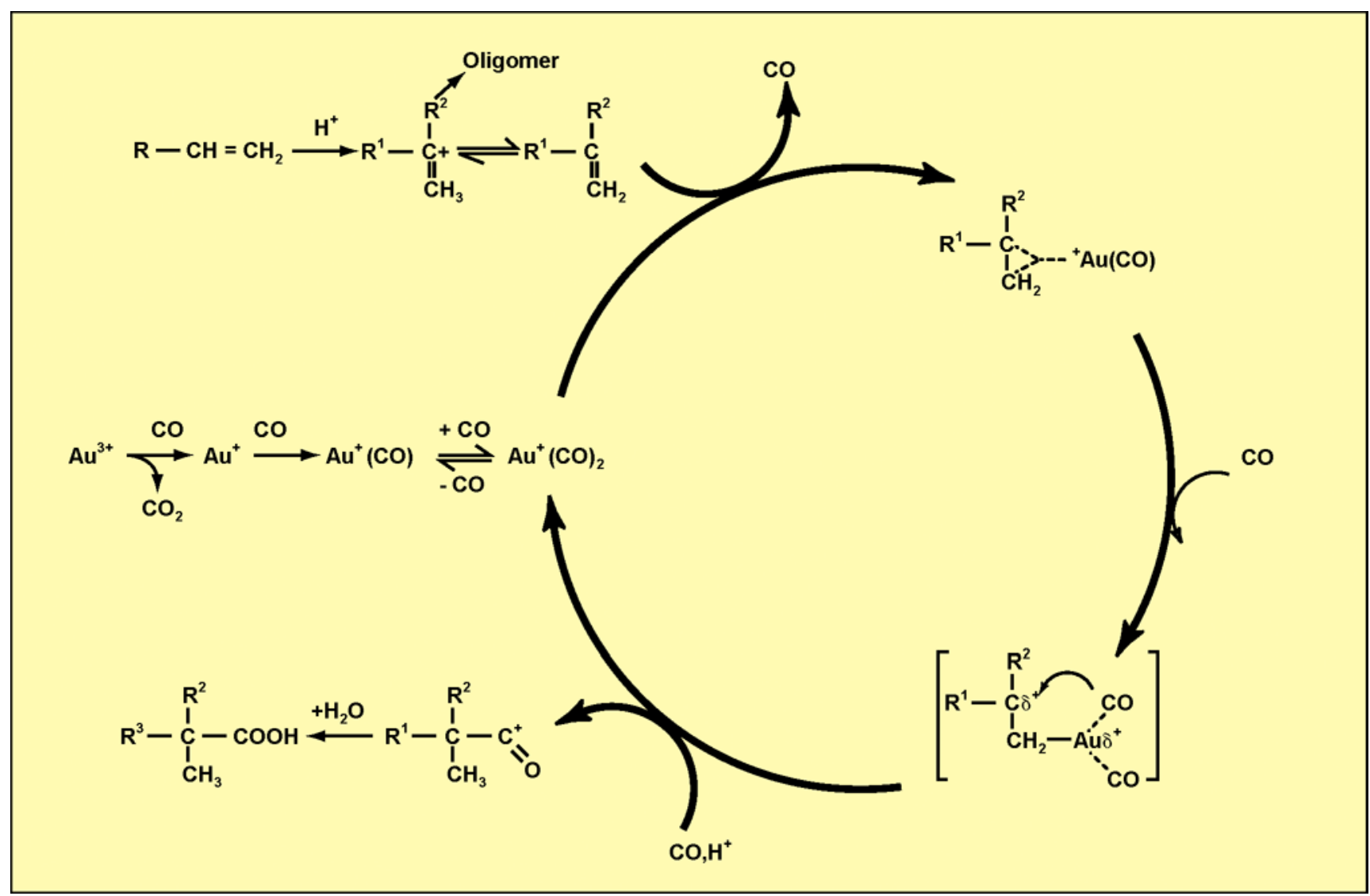

Figure 7 Proposed mechanism for the carbonylation of olefins using a soluble gold catalyst. (Based on reference 29) 
A chemical description of a gold carbonyl catalyst is given in Figure 6 (29). Gold(III) oxide $\left(\mathrm{Au}_{2} \mathrm{O}_{3}\right)$ in concentrated sulfuric acid is reduced by carbon monoxide to form $\left[\mathrm{Au}(\mathrm{CO})_{n}\right]$ in one step. The gold monocarbonyl (1) and the gold dicarbonyl (2) coexist in this solution. This non-classical gold(I) carbonyl solution has proved to be an effective catalyst for the formation of $t$-carboxylic acids from olefins at room temperature and atmospheric pressure but the turnover numbers are very small. The proposed mechanism is given in Figure 7. This is an example of a Koch reaction, also known to be catalysed by copper and silver.

Gold(I) and gold(III) alkoxides have been shown to catalyse the condensation of benzaldehyde with compounds containing an active methylene group, $\mathrm{CH}_{2}(\mathrm{X}) \mathrm{Y}$, again with very low turnover numbers $(26$, 30):

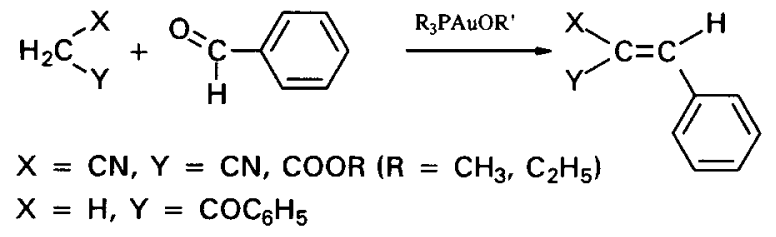

Best results were obtained with gold(I) catalysts of the more electron-withdrawing alkoxides: $\mathrm{R}_{3} \mathrm{PAu}\left(\mathrm{OR}^{\prime}\right), \mathrm{R}$ $=\mathrm{Ph}, \mathrm{C}_{6} \mathrm{H}_{11} ; \mathrm{R}^{\prime}=\mathrm{OCH}_{2}\left(\mathrm{CF}_{3}\right)_{2}$. The proposed mechanism is shown in Figure 8: the alkoxide IV initially reacts with $\mathrm{CH}_{2}(\mathrm{X}) \mathrm{Y}$ from which it abstracts a proton to form the corresponding alcohol and an $\mathrm{Au}^{-}$ $\mathrm{CH}(\mathrm{X}) \mathrm{Y}$ species $\mathbf{V}$ (such compounds themselves catalyse the reaction, but less efficiently). The carbonyl group of benzaldehyde inserts into the $\mathrm{Au}-\mathrm{C}$ bond of $\mathbf{V}$ and the resulting complex deprotonates either $\mathrm{CH}_{2}(\mathrm{X}) \mathrm{Y}$ or the alcohol, to reform IV or $\mathbf{V}$; the initially formed alcohol (VI) loses water spontaneously.

Another useful example of homogeneous catalysis which appears to involve an organogold intermediate is the cyclization of alkynyl amines such as $\mathrm{R}^{1} \mathrm{C}=\mathrm{C}\left(\mathrm{CH}_{2}\right)_{3} \mathrm{CHR}^{2} \mathrm{NH}_{2}$ (Figure 9) catalysed by $\mathrm{Na}\left[\mathrm{AuCl}_{4}\right]$ (31). It was suggested that a cyclic intermediate is formed by exo-dig addition of Au and $\mathrm{N}$ across the triple bond which then undergoes protonolysis and isomerization. The reaction mixture rapidly decolourizes, implying the involvement of gold(I), and the most likely mechanism would be via initial formation of a $\pi$-alkyne complex. The coordinated triple bond would then be open to nucleophilic attack by the amine group; under sufficient dilution this would occur intramolecularly.

The 'Hyashi' ferrocenyl gold catalyst which is

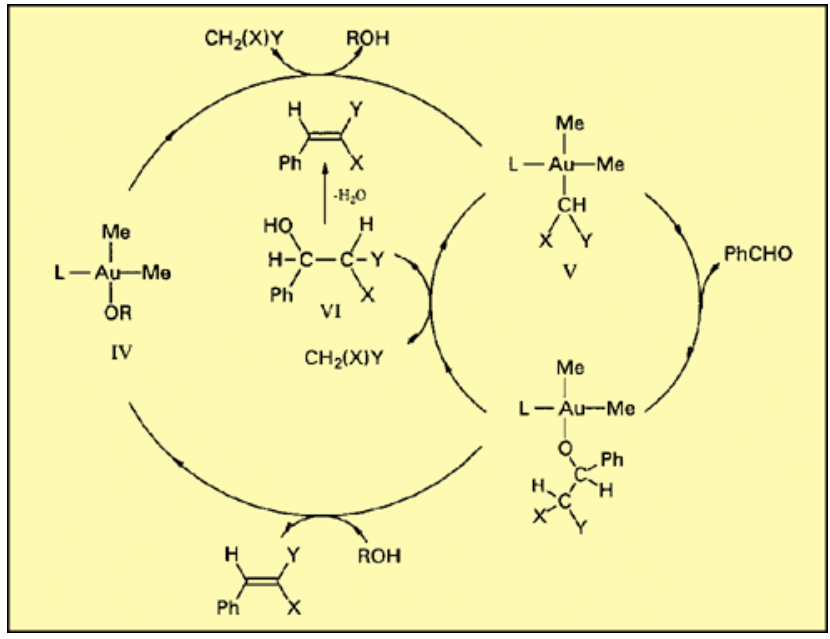

Figure 8 Proposed mechanism for Komiya condensation reaction. (Based on references 26 and 30 )

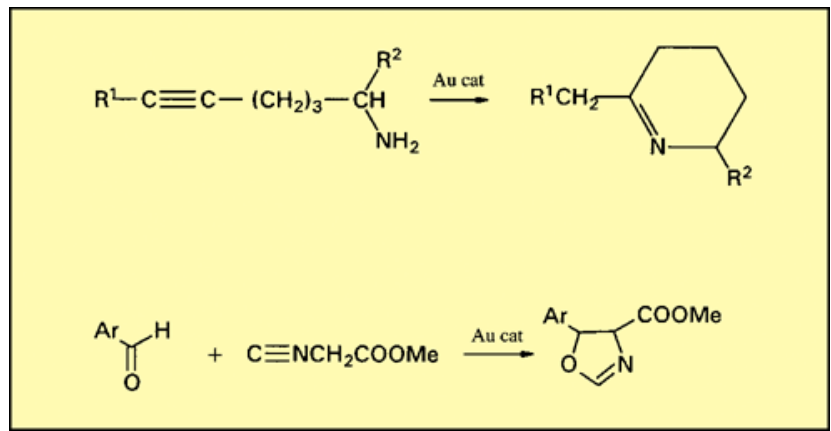

Figure 9 Examples of homogeneous catalysis using gold catalysts. (Based on references 26, 31 and 32)

achieving prominence for the synthesis of asymmetric heterocycles (Figure 9) is also a gold(I) complex, although its mode of action involves formation of an isonitrile complex of gold, rather than an organometallic intermediate (32). There is some evidence that $\left[\mathrm{AuCl}_{4}\right]^{-}$catalyses the addition of nucleophiles such as amines and alcohols to isonitriles (33) and that the mechanism involves the formation of carbene complexes (34), but in all cases copper(I) is a far better catalyst.

The possibility of commercial relevance for gold homogeneous catalysis is indicated by the publication of patents by Enichem SPA, Italy naming Calderazzo et al as inventors (35). These patents claim a homogeneous catalyst system for the preparation of olefin (ethylene, $\alpha$-olefin) / carbon monoxide alternating copolymers. The catalysts consist of at least one Group 11 metal salt $(\mathrm{Cu}, \mathrm{Ag}, \mathrm{Au})$, a $\mathrm{P}$ - or $\mathrm{N}$ containing bidentate chelating base, and an oxidizing agent (nitrosium tetrafluoroborate or $p$-benzoquinone) 
which is not hydrophilic. The process is used for copolymerizing ethylene and/or other olefinic monomers, either as individuals or as a mixture of two or more, with carbon monoxide. The method simply involves mixing the components together in a solvent. Appropriate mixtures of olefins can be employed to 'tailor-make' polymer properties such as melting point, glass transition temperature and processability.

\section{SUPPORTED HOMOGENEOUS CATALYSIS SYSTEMS}

There are some examples of homogeneous catalysts which are known to catalyse reactions after being supported on oxides. For example, Schmid (36) has practical evidence for the importance of 55 atom clusters (particle diameter $1.4 \mathrm{~nm}$ ) and has described the preparation of $\mathrm{Au}_{55} \mathrm{Cl}_{6}\left(\mathrm{PPh}_{3}\right)_{12}$. The isomerization of hexanes (2,2-dimethylbutane to $n$-hexane) was studied using $1 \% \mathrm{Au}_{55}$ on $\mathrm{TiO}_{2}$ (anatase). $\mathrm{Au} / \mathrm{Pd}$ colloids, in which the gold is coated with palladium show enhanced catalytic activity for the hydrogenation of 2-hexyne to 2-hexene, and palladium coated with gold is also active, even though pure gold is inactive.

A phosphine-stabilized mononuclear gold complex, $\mathrm{Au}\left(\mathrm{PPh}_{3}\right)\left(\mathrm{NO}_{3}\right)$, and a phosphine-stabilized gold cluster, $\left[\mathrm{Au}_{9}\left(\mathrm{PPh}_{3}\right)_{8}\right]\left(\mathrm{NO}_{3}\right)_{2}$, have been used as precursors for supported gold catalysts. Both complexes were inactive for carbon monoxide oxidation if supported on oxides such as $\alpha-\mathrm{Fe}_{2} \mathrm{O}_{3}$, titania and silica, whereas the compounds supported on oxides when treated under air or in carbon monoxide or in $5 \% \mathrm{H}_{2} / \mathrm{Ar}$ atmosphere were found to be active for carbon monoxide oxidation. The catalytic activity depends not only on the conditions of treatment but also on the kind of the precursor and the supports used. The catalysts derived from the first complex showed higher activity than those derived from the second. $\alpha-\mathrm{Fe}_{2} \mathrm{O}_{3}$ and titania were much more efficient supports than silica for the gold particles $(37,38)$.

Pignolet has studied catalytic applications of platinum- and palladium-gold clusters. The $\mathrm{H}_{2} / \mathrm{D}_{2}$ equilibrium was investigated using $\left[\mathrm{Pt}\left(\mathrm{AuPPh}_{3}\right)_{8}\right]\left(\mathrm{NO}_{3}\right)_{2}$. There was a rate-determining dissociation of $\mathrm{PPh}_{3}$. The clusters were then supported on alumina and silica and the $\mathrm{H}_{2} / \mathrm{D}_{2}$ equilibrium again studied. If activated at moderate temperatures, the cluster could be desorbed after catalysis. It was concluded that partial and reversible ligand desorption and/or cluster distortion takes place on the support giving rise to significant effects on activation. Treatment under hydrogen increases this effect. Magic Angle Spinning solid state NMR was used to characterize the surface species (39).

\section{CONCLUSIONS}

Present knowledge confirms that catalysis by gold is distinctly different from catalysis using other precious metals, both in the techniques required to prepare the catalysts and in the ways that they function during reactions, $i e$ some aspects are unique to gold (1). There are a number of areas where gold catalysis has potential for applications, both in the environmental control and chemical processing areas. In depth study of gold catalyst technology is likely to lead to a better understanding of the effects so far recorded and should provide a sound basis for the use of this technology in these fields.

Gold catalysts could have promise for low light off applications, but sintering problems may have to be surmounted at higher temperatures, where for example platinum ( $m$ p $2042 \mathrm{~K}$ ) has the advantage of possessing a much higher melting point than gold ( $\mathrm{m} \mathrm{p}$ $1337 \mathrm{~K}$ ). As a result, the Tammann temperature, at which the metal particles begin to sinter is significantly lower for gold. Strong bonding between the gold and its support could, however, overcome this potential disadvantage. For removal of noxious gases such as carbon monoxide and nitrogen oxides supported gold also has potential, and the removal of hydrocarbons is a distinct possibility.

The potential of supported gold catalysts for hydrogenation of carbon oxides and for catalysis of the water gas shift has already been examined and could with benefit be further developed. Homogeneous catalysis has been studied by some industrial research organizations; and the dramatic recent breakthrough using gold catalysts in solution for the addition of methanol to triple bonds could eventually have far reaching consequences. As a result, the hypotheses previously put forward to rationalize the ineffectiveness of gold as a homogeneous catalyst will need to be revised.

As we have seen, gold was previously regarded as an inferior catalyst compared with the other precious metals (1), but the examples given in this pair of articles clearly demonstrate that there are a growing number of reactions where it can be the catalyst of choice. These examples encompass the fields of 
heterogeneous, homogeneous and supported homogeneous catalysis.

\section{ACKNOWLEDGEMENTS}

The author is grateful for supply of information by $\mathrm{Dr}$ Masatake Haruta (Osaka National Research Institute, Japan) and for helpful discussions with Professors Geoffrey Bond (Brunel University, Uxbridge, UK) and Graham Hutchings (Cardiff University, UK). He is also indebted to Professor R V Parish (UMIST, UK) for information on homogeneous catalysis, received prior to publication. Figures 1-5 were re-drawn from the original literature during preparation for a review article entitled 'Catalysis by Gold' by $\mathrm{G} C$ Bond and $\mathrm{D} \mathrm{T}$ Thompson and recently accepted for publication in Catalysis Reviews - Science and Engineering. Thanks are also due to Dr Lucy Thompson for literature searches and to the IMPI for permission to publish the whole of the Toronto talk (see footnote to p12).

\section{ABOUT THE AUTHOR}

David Thompson has participated in and managed upstream, basic and applied research activities in universities (Imperial College, London and University of California, Los Angeles), ICI, and Johnson Matthey. His published papers are concerned with catalysis and materials topics, particularly those involved with precious metals, as well as with organic and inorganic chemistry. He is Technical Editor of Gold Bulletin and Consultant to World Gold Council. In his freelance work as a chemical consultant he advises on catalyst system design for chemical processing, pollution control and gas detection. Some of this work is performed in collaboration with universities, and he helps industrial organizations to optimize their contacts with university research. He has contributed to and assisted in the editing of a new book to be published in 1999 entitled 'The Company of the Future'.

\section{REFERENCES}

1 D.T. Thompson, Gold Bull, 1998, 31, 111

2 R.D. Waters, J.J. Weimer and J.E. Smith, Catal. Lett, 1995, 30, 181

3 M. Haruta, Now and Future, 1992, 7, 13

4 M. Haruta, Catal. Today, 1997, 36, 153; Catalysis Surveys of Japan, 1997, 1, 61
5 H. Sakurai and M Haruta, Catal. Today, 1996, 29, 361

6 D. Andreeva, V. Idakiev, T. Tabakova and A. Andreev, J. Catal., 1996, 158, 354

7 L.I. Ilieva, D.H. Andreeva and A.A. Andreev, Thermochim. Acta, 1997, 292, 169

8 H. Sakurai, A. Ueda, T. Kobayashi and M. Haruta, Chem. Commun., 1997, 271

9 S. Qui, R. Onishi and M. Ichikawa, J. Phys. Chem, 1994, 98, 2719

10 T.M. Salama, R. Ohnishi and M. Ichikawa, J. Chem. Soc, Faraday Trans, 1996, 92, 301

11 T.M.Salama, R. Ohnishi, T. Shido and M. Ichikawa, J. Catal. 1996, 162, 169

12 T.M. Salama, R, Ohnishi and M. Ichikawa, Stud. Surf. Sci. Catal., 1997, 105, 1571

13 G. R. Bamwenda, A. Obuchi, A. Ogata, J. Oi, S. Kushiyama and K. Mizuno, J. Mol. Catal, A.Chemical, 1997, 126, 151

14 A. Ueda and M Haruta, Appl. Catal. B. Environmental, 1996, 285, 81

15 A. Ueda and M. Haruta, Appl. Catal. B: Environmental, 1998, 18, 453

16 T. Aida, R. Higuchi and H Niiyama, Chem. Lett, 1990, 2247

17 Z. Hao, L.An, J. Zhou and H. Wang, React. Kin. Catal. Lett., 1996, 59, 295

18 J. Schwank, Gold Bull, 1985, 18, 2; see also Gold Bull, 1983, 16, 103

19 G.J. Hutchings, Gold Bull., 1996, 29, 123

20 M. Haruta, S.Tsubota, T. Kobayashi, H. Kageyama, M.J. Genet and B. Delmon, J. Catal, 1993, 144, 175

21 G.R. Bamwenda, S. Tsubota, T. Nakamura and M. Haruta, Catal. Lett., 1997, 44, 83

22 L.D. Burke and P.F. Nugent, Gold Butl., 1998, 31, 39

23 F.E. Wagner, S. Galvagno, C. Milone, A.M. Visco, L. Stievano and S.D. Calogero, J. Chem. Soc, Faraday Trans, 1997, 93, 3403

24 A.M. Visco, A. Donato, C. Milone and S. Galvagno, React. Kinet. Catal. Lett., $1997,61,219$

25 S. Mimico, S. Scrire, C. Crisafulli, A.M. Visco and S. Galvagno, Catal. Lett., 1997, 47, 273

26 R.V. Parish, Gold Bull., 1998, 31, 14

27 A. Tamaki, S.A. Magennis and J.K. Kochi, J. Am. Chem. Soc, 1974, 96, 6140

28 J.H.Teles, S. Brode and M. Chabanas, Angew. Chem. Int. Ed, 1998, 37, 1415

29 Q. Xu, Y. Imamura, M. Fujiwara and Y. Souma, J. Org. Chem., 1997, 62, 1594

30 S. Komiya, T. Sone, Y. Usui, M. Hirano and A. Fukuoka, Gold Bull., 1996, 29, 131

31 Y. Fukada and K. Utimoto, Synthesis, 1991, 975

32 V.A. Soloshonok and T Hayashi, Tetrahedron Asymm., 1994, 6, 1091, and references therein

33 T. Saegusa, Y. Ito, S. Kobayashi, K. Hirota and H. Yoshioka, Bull. Chem. Soc. Japan, $1969,42,3310$

34 J.E. Parkes and A.L. Balch, J. Organomet. Chem., 1974, 71, 453

35 F. Calderazzo, F. Garbassi, G. Lugli and A. Sommazzi, European Patent 200695 930311, 1993 (EP 560455 A1, EP 560456 A1)

36 G. Schmid, 'Progress in the Science and Technology of Gold', Hanau, June 1996, see Gold Bull., 1996, 29, 105

37 Y. Yuan, K. Asakura, H. Wan, K. Tsai and Y. Lwasawa, Catal, Lett., 1996, 42, 15

38 Y. Yuan, A.P. Kozlova, K. Asakura, H. Wan, K.Tsai and Y. Twasawa, J. Catal., 1997, 170,191

39 L. Pignolet, 'Progress in the Science and Technology of Gold', Hanau, June 1996, see Gold Bull., 1996, 29, 70, 105 